\title{
A IMPORTÂNCIA DA EDUCAÇÃO FÍSICA PARA O DESENVOLVIMENTO MOTOR DE CRIANÇAS E JOVENS COM TRANSTORNOS DO ESPECTRO AUTISTA
}

\section{THE IMPORTANCE OF PHYSICAL EDUCATION FOR MOTOR DEVELOPMENT OF CHILDREN AND YOUNG PEOPLE WITH AUTISTIC SPECTRUM DISORDERS}

\author{
PRAXEDES, Matheus Ramos da Cruz Jomilto ${ }^{1}$
}

\begin{abstract}
RESUMO
O estudo objetivou identificar as estratégias utilizadas com uso da educação física e suas possíveis contribuições para o aprimoramento motor de crianças e jovens com Trasntorno do Espectro Autista (TEA). Foi realizada uma revisão bibliográfica com artigos e dissertações completos publicados entre o período de 2000 a 2016 nas bases de dados Pubmed, Scielo, Pepsic, Lilacs e Latindex. Os artigos indicaram a utilização de jogos, práticas esportivas, atividades aquáticas, gincanas, exercícios de fortalecimento muscular, de equilíbrio e psicomotricidade, práticas motoras com trampolins e atividades ao ar livre. As intervenções demonstraram diminuição de estereotipias, aumento do repertório motor, desenvolvimento da coordenação motora, do equilíbrio, da agilidade e do controle postural, e melhorias em aspectos sociais e comunicativos. Conclui-se que a educação física pode contribuir para o desenvolvimento motor de crianças e jovens com TEA por meio de um programa de exercícios especificamente elaborado.
\end{abstract}

Palavras-Chave: Autismo; Educação Física; Desenvolvimento Motor.

\begin{abstract}
This study aimed to identify the strategies used with the use of physical education and its possible contributions to the motor improvement of children and adolescents with ASD. A bibliographic review was done with articles and complete dissertations published between the period of 2000 to 2016 in the Pubmed, Scielo, Pepsic, Lilacs and Latindex databases. The articles indicated the use of games, sports practices, water activities, gymnastics, activities muscle strengthening, balance and psychomotor exercises, motor practices with trampolines and outdoor activities. The results point to a decrease in stereotyped movements, an increase in motor repertoire, development of motor coordination, improvement of balance, agility and postural control, and the development of social and communicative aspects. It is concluded that physical education can contribute to the motor development of children and adolescents with ASD By means of a specifically designed exercise program.
\end{abstract}

KeYWORDS: Autism; Physical Education; Motor Development.

${ }^{1}$ Universidade do Estado do Rio de Janeiro - IEFD. e-mail: matheusramoss013@gmail.com 


\section{INTRODUÇÃO}

Segundo o Diagnostic and statistical manual of mental disorders (DSM), o Transtorno do Espectro Autismo (TEA) pode ser entendido como um transtorno de neurodesenvolvimento, que surge na infância, resultando em déficits nas dimensões sociocomunicativa e comportamental do indivíduo (APA, 2013).

O termo "autismo" é oriundo da palavra "autos" que significa "próprio" ou "de si mesmo" (SOUSA; SANTOS, 2005). Em 1943, o conceito do Autismo foi primeiramente mencionado pelo psiquiatra Leo Kanner como uma psicose caracterizada por um extremo isolamento, alterações na comunicação, rituais repetitivos e obsessivos, e manifestações de comportamentos motores repetitivos (COELHO; SANTO, 2006).

Crianças e jovens acometidos pelo TEA podem apresentar dificuldade de relacionar-se com outras pessoas, juntamente com complicações na articulação de palavras e nas expressões de personalidade (SOUZA; FACHADA, 2012; MATIKO OKUDA et al, 2010). Outras características peculiares também podem ser observadas, tais como: a existência de comportamento hiperativo (TREVARTHEN; DANIEL, 2005), apego inadequado a objetos e rotinas (ORRÚ, 2002), além de uma série de alterações nos domínios comportamentais, perceptivo-motores e cognitivos (LECAVALLIER, 2006).

No que se refere ao campo motor, há evidências que apontam alterações negativas em aspectos inerentes ao desenvolvimento motor. Orrú (2002) afirma que crianças com TEA podem manifestar atrasos no desenvolvimento da marcha. Diversos autores também apontam para a existência de déficits em outros fatores importantes como o equilíbrio e o esquema corporal e, a organização espacial e temporal (LARSON et al, 2008; LOURENÇO et al, 2016; RICHLER et al., 2007; FONTES, 2013), além de dificuldades nos movimentos oculares e movimentos de controle motor fino (ESPOSITO; PASCA, 2013; JASMIN et al., 2008).

$\mathrm{Na}$ literatura investigada, há evidências de que crianças que não tiveram uma ampla experiência motora podem ter o seu desenvolvimento motor comprometido e também apresentar dificuldades de aprendizagem (FONSECA, 1988; GALLAHUE; OZMUN, 2005, LE BOUCH, 2008, ROSA NETO, 2009; LUCENA et al, 2010).

Diante das possíveis alterações negativas que crianças e jovens com TEA podem apresentar em seu desenvolvimento motor, diversas intervenções com a utilização de atividades motoras que integram o ensino da educação física escolar vem sendo estudadas para auxiliar no aprimoramento motor destes indivíduos (SOWA; MEULENBROEK, 2012; ANDERSON-HANLEY; TURECK; SCHNEIDERMAN, 2011; CHEDALVI, 2014; CHICON; SÁ; FONTES, 2013; FRAGALA-PINKHAM, 2005; LOURENÇO et al, 2016). 
DOI: $10.12957 /$ e-mosaicos.2018.33622

Há ainda evidências que apontam que, por meio da atividade física e da expressão corporal, é possível desenvolver aspectos comunicativos e sociais de indivíduos com TEA (LÔ; GOERL, 2010; TOMÉ, 2007). Constatando que, independentemente dos tipos de intervenção, a utilização da prática de atividades físicas regulares e ou lúdicas podem proporcionar melhoria da proficiência motora (WROTNIAK et al., 2006).

No entanto, ainda não é sabido como cada tipo de atividade pode contribuir para o progresso do indivíduo. Diante disso, torna-se importante reunir e investigar como a educação física pode auxiliar no aprimoramento de aspectos motores de crianças e jovens com TEA. Assim, o presente trabalho tem como objetivo, identificar as estratégias motoras utilizadas e suas possíveis contribuições para o aprimoramento motor de crianças e jovens com TEA.

\section{Metodologia}

Este trabalho caracteriza-se por uma pesquisa de revisão bibliográfica. Para a investigação, foram utilizados artigos e dissertações completos e publicados em inglês, espanhol e português, no período entre 2000 e 2016.

A busca dos estudos foi realizada por meio das bases de dados eletrônicas Pubmed, Scielo, Pepsic, Lilacs e Latindex. Para o refinamento da estratégia de busca, foram utilizados os seguintes descritores chave: Autismo, Educação física, Desenvolvimento motor e Comportamento motor. Com isso obteve-se um total de 85 produções, sendo escolhidas para presente estudo 46, discriminados em 42 artigos e 4 dissertações.

Os materiais utilizados foram os que tiveram maior proximidade com o tema proposto, sendo preconizados estudos realizados com crianças e jovens diagnosticados com TEA e que utilizaram estratégias com o uso de atividades físicas e motoras. (Figura 1).

Figura 1 - Fluxograma da Metodologia de busca dos estudos

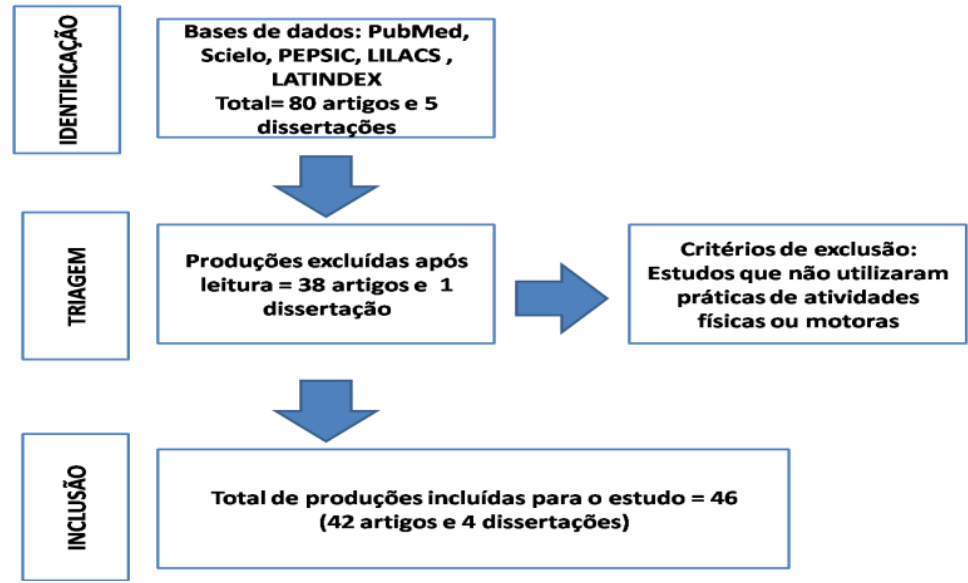

Fonte: Elaborado pelo autor 


\section{RESULTADOS E discuSSÃo}

$\mathrm{Na}$ busca realizada, foi possível observar uma grande diversidade de estratégias que apresentaram benefícios para os aspectos motores e sóciocomunicativos. O Quadro 1 demonstra estudos com diferentes tipos de intervenção, com os autores de cada pesquisa e os resultados obtidos.

\section{Quadro 1 - Estudos realizados com a utilização de programas de atividade física para indivíduos com TEA}

\begin{tabular}{|c|c|c|}
\hline Autores & Tipos de Intervenção & Resultados \\
\hline $\begin{array}{l}\text { ANDERSON-HANLEY; } \\
\text { TURECK; } \\
\text { SCHNEIDERMAN, } 2011\end{array}$ & $\begin{array}{l}2 \text { estudos pilotos com um total } \\
\text { de } 22 \text { indivíduos adolescentes } \\
\text { diagnosticados com TEA que } \\
\text { participaram de sessões com o } \\
\text { uso de exergames durante o } \\
\text { período de } 2 \text { semanas com } \\
\text { duração de } 25 \text { minutos em cada } \\
\text { sessão. }\end{array}$ & $\begin{array}{l}\text { Diminuição significativa de } \\
\text { comportamentos motores } \\
\text { repetitivos após a utilização dos } \\
\text { exergames. }\end{array}$ \\
\hline $\begin{array}{l}\text { BAGAROLLO; RIBEIRO; } \\
\text { PANHOCA, } 2013\end{array}$ & $\begin{array}{l}1 \text { criança de } 4 \text { anos } \\
\text { diagnosticada com TEA, } \\
\text { juntamente com } 3 \text { crianças de } \\
\text { mesma idade e diagnosticadas } \\
\text { com o mesmo quadro, } \\
\text { participaram de sessões } \\
\text { terapêuticas semanais com } \\
\text { duração de } 30 \text { minutos com o } \\
\text { uso de brinquedos, jogos e } \\
\text { atividades lúdicas. }\end{array}$ & $\begin{array}{l}\text { Foi possível observar que em } \\
\text { alguns momentos os indivíduos } \\
\text { utilizavam juntos o mesmo } \\
\text { brinquedo. Além disso, a } \\
\text { criança de } 4 \text { anos também } \\
\text { demonstrou interesse em jogos } \\
\text { de faz de conta e na } \\
\text { simbolização de papéis em } \\
\text { determinadas atividades, } \\
\text { respeitando a sequência de } \\
\text { ações, demonstrando } \\
\text { manifestações de conhecimento } \\
\text { em relação aos utensílios } \\
\text { utilizados para cada ação. }\end{array}$ \\
\hline BOATO et al, 2014 & $\begin{array}{l}1 \text { aluno de } 10 \text { anos } \\
\text { diagnosticado com TEA } \\
\text { participou de oficinas com a } \\
\text { utilização de atividades de } \\
\text { expressão corporal e dança, } \\
\text { duas vezes na semana, durante } \\
\text { o período de } 1 \text { ano. }\end{array}$ & $\begin{array}{l}\text { Foram constatadas mudanças } \\
\text { no comportamento sócio- } \\
\text { emocional do aluno, } \\
\text { manifestando, em alguns } \\
\text { momentos, livre expressão } \\
\text { corporal e ações comunicativas. }\end{array}$ \\
\hline $\begin{array}{l}\text { FALKENBACH; DIESEL; } \\
\text { OLIVEIRA, } 2010\end{array}$ & $\begin{array}{l}1 \text { criança diagnosticada com } \\
\text { TEA, participou de aulas } \\
\text { semanais de psicomotricidade } \\
\text { com duração de } 90 \text { minutos por } \\
\text { sessão, durante o período de } \\
\text { aproximado de } 6 \text { meses. }\end{array}$ & $\begin{array}{l}\text { O aluno com TEA demonstrou, } \\
\text { durante as aulas, manifestações } \\
\text { de afetividade, socialização e } \\
\text { iniciativa para a participação de } \\
\text { algumas atividades. }\end{array}$ \\
\hline
\end{tabular}


e-Mosaicos - Revista Multidisciplinar de Ensino, Pesquisa, Extensão e Cultura do Instituto de Aplicação Fernando Rodrigues da Silveira (CAp-UERJ) V. 7 - N. 14 - ABRIL 2018 - ISSN: 2316-9303

DOI: $10.12957 /$ e-mosaicos.2018.33622

\begin{tabular}{|c|c|c|}
\hline $\begin{array}{c}\text { FRAGALA-PINKHAM et al, } \\
2005\end{array}$ & $\begin{array}{l}9 \text { crianças com idades entre } 5 \text { e } \\
9 \text { anos diagnosticadas com } \\
\text { autismo, paralisia cerebral, } \\
\text { atraso de desenvolvimento, } \\
\text { dispraxia e lesão cerebral, } \\
\text { participaram durante } 26 \\
\text { semanas de programas de } \\
\text { atividade física, sendo } 14 \\
\text { semanas com atividades em } \\
\text { grupo e } 12 \text { semanas com } \\
\text { atividades em casa, que } \\
\text { consistiam em práticas de } \\
\text { dança, gincanas, jogos de bola, } \\
\text { jogos de siga o líder, exercícios } \\
\text { de fortalecimento dos músculos } \\
\text { superiores do corpo e do tronco } \\
\text { com theraband, bola, pesos } \\
\text { livres e peso corporal. Este } \\
\text { programa teve frequência } \\
\text { semanal de } 2 \text { vezes por semana. }\end{array}$ & $\begin{array}{l}6 \text { das } 9 \text { crianças apresentaram } \\
\text { melhorias em sua resistência } \\
\text { cardiovascular, gasto de energia } \\
\text { e no tempo de execução de } \\
\text { caminhadas; } 7 \text { apresentaram } \\
\text { melhora na força musculo- } \\
\text { esquelética; } 6 \text { apresentaram } \\
\text { melhora na coordenação } \\
\text { motora grossa e em habilidades } \\
\text { funcionais e } 5 \text { apresentaram } \\
\text { melhorias em sua flexibilidade. }\end{array}$ \\
\hline $\begin{array}{l}\text { FRAGALA- PINKHAM; } \\
\text { HALEY; O'NEIL, } 2008\end{array}$ & $\begin{array}{l}6 \text { crianças ( } 3 \text { com TEA e } 3 \\
\text { diagnosticadas com Transtorno } \\
\text { global do desenvolvimento } \\
\text { participaram durante } 14 \\
\text { semanas de sessões de } \\
\text { atividades aquáticas com } \\
\text { duração de } 30 \text { a } 50 \text { minutos. }\end{array}$ & $\begin{array}{l}\text { Significativa redução no tempo } \\
\text { para completar uma meia milha } \\
\text { em corrida e caminhada, mas a } \\
\text { força muscular e a flexibilidade } \\
\text { não demonstraram resultados } \\
\text { significativos. }\end{array}$ \\
\hline HINCKSON et al, 2013 & $\begin{array}{l}17 \text { indivíduos com idades entre } \\
7 \text { e } 21 \text { anos, diagnosticados com } \\
\text { autismo e deficiência intelectual, } \\
\text { foram submetidos a sessões de } \\
\text { atividades físicas e aquáticas } \\
\text { durante o período de } 10 \\
\text { semanas. Juntamente com as } \\
\text { sessões, os sujeitos do estudo } \\
\text { também receberam } \\
\text { acompanhamento nutricional e } \\
\text { aconselhamentos em relação ao } \\
\text { estilo de vida, com frequencia } \\
\text { semanal de } 2 \text { vezes por semana, } \\
\text { com } 60 \text { minutos de duração por } \\
\text { sessão. }\end{array}$ & $\begin{array}{l}\text { Os indivíduos apresentaram } \\
\text { melhorias na marcha } \\
\text { sustentada por } 6 \text { minutos. Os } \\
\text { pais também relataram que } \\
\text { houve uma diminuição } \\
\text { significativa do consumo de } \\
\text { doces, após a intervenção. }\end{array}$ \\
\hline MACHADO, 2001 & $\begin{array}{l}5 \text { crianças de } 1 \text { a } 3 \text { anos } \\
\text { participaram de um atendimento } \\
\text { psicomotriz com a utilização de } \\
\text { atividades com brinquedos, } \\
\text { jogos e atividades de imitação } \\
\text { durante } 1 \text { ano. }\end{array}$ & $\begin{array}{l}\text { Pode- se evidenciar mudanças } \\
\text { qualitativas em aspectos } \\
\text { motores das crianças e indícios } \\
\text { de simbolização, } \\
\text { comunicabilidade, interação e } \\
\text { afetividade. }\end{array}$ \\
\hline
\end{tabular}


e-Mosaicos - Revista Multidisciplinar de Ensino, Pesquisa, Extensão e Cultura do Instituto de Aplicação Fernando Rodrigues da Silveira (CAp-UERJ) V. 7 - N. 14 - ABRIL 2018 - ISSN: 2316-9303

DOI: $10.12957 /$ e-mosaicos.2018.33622

\begin{tabular}{|c|c|c|}
\hline $\begin{array}{l}\text { YILMAZ et al, } \\
2004\end{array}$ & $\begin{array}{l}\qquad 1 \text { criança de } 9 \text { anos } \\
\text { diagnosticada com autismo } \\
\text { participou de treinamentos de } \\
\text { natação } 3 \text { vezes por semana } \\
\text { com duração de } 60 \text { minutos por } \\
\text { sessão, durante o período de } 10 \\
\text { semanas. }\end{array}$ & $\begin{array}{l}\quad \text { Foram constatadas } \\
\text { melhorias no equilíbrio, na } \\
\text { agilidade, na velocidade, na } \\
\text { força muscular das } \\
\text { extremidades superior e } \\
\text { inferior, flexibilidade e aptidão } \\
\text { cardiovascular. Além disso, } \\
\text { também foram observadas } \\
\text { diminuições nos } \\
\text { comportamentos } \\
\text { estereotipados. }\end{array}$ \\
\hline LOURENÇO et al, 2016 & $\begin{array}{l}17 \text { crianças com idades entre } 4 \\
\text { e } 10 \text { anos de idade, } \\
\text { participaram de um programa } \\
\text { de exercícios com a utilização de } \\
\text { trampolins durante um período } \\
\text { de } 20 \text { semanas, com sessões } \\
\text { realizadas uma vez por semana } \\
\text { durante } 45 \text { minutos. }\end{array}$ & $\begin{array}{l}\text { Após a intervenção, pode ser } \\
\text { observado que as crianças com } \\
\text { TEA obtiveram melhorias na } \\
\text { proficiência motora, além de } \\
\text { melhorias em outros aspectos } \\
\text { motores, como: coordenação } \\
\text { sequencial e simultânea entre } \\
\text { os membros inferiores e } \\
\text { superiores, melhorias no } \\
\text { equilíbrio, na velocidade, na } \\
\text { agilidade, na força e na } \\
\text { coordenação motora dos } \\
\text { membros superiores. }\end{array}$ \\
\hline $\begin{array}{c}\text { SOWA; MEULENBROEK, } \\
2012\end{array}$ & $\begin{array}{l}\text { Foi realizada uma meta- análise } \\
\text { que avaliou } 16 \text { estudos } \\
\text { comportamentais relatando um } \\
\text { total de } 133 \text { crianças e adultos } \\
\text { que receberam um atendimento } \\
\text { com programas de atividades } \\
\text { físicas estruturadas em um } \\
\text { contexto individual ou em } \\
\text { atividades em grupo. }\end{array}$ & $\begin{array}{l}\text { Todas as intervenções } \\
\text { demonstraram progressos } \\
\text { referentes aos aspectos } \\
\text { motores avaliados. Foi } \\
\text { constatado que os programa de } \\
\text { atividades físicas individuais } \\
\text { expressaram resultados mais } \\
\text { significativos que nos } \\
\text { programas com atividades em } \\
\text { grupo nos domínios motores e } \\
\text { sociais. }\end{array}$ \\
\hline SOUZA; FACHADA, 2012 & $\begin{array}{l}11 \text { pais de crianças com TEA } \\
\text { responderam questionários com } \\
\text { perguntas referentes ao } \\
\text { comportamento de seus filhos } \\
\text { após a participação de um } \\
\text { programa com atividades } \\
\text { esportivas, ações socioculturais } \\
\text { e palestras de assistência social, } \\
\text { técnicas de relaxamento, } \\
\text { exercícios de psicomotricidade, } \\
\text { jogos, dinâmicas pedagógicas e } \\
\text { acompanhamento psicológico } \\
\text { direcionado aos familiares das } \\
\text { crianças atendidas. }\end{array}$ & $\begin{array}{l}\text { Ao entrevistar } 11 \text { pais e } \\
\text { responsáveis, } 7 \text { dos pais } \\
\text { afirmaram ter tido uma razoável } \\
\text { ou muita melhora nos } \\
\text { movimentos estereotipados de } \\
\text { seus filhos, } 8 \text { disseram ter } \\
\text { notado razoável ou muita } \\
\text { melhora na agressividade, } 10 \\
\text { afirmaram conseguir se } \\
\text { comunicar melhor com seus } \\
\text { filhos e } 10 \text { perceberam seus } \\
\text { filhos mais carinhosos. }\end{array}$ \\
\hline
\end{tabular}


e-Mosaicos - Revista Multidisciplinar de Ensino, Pesquisa, Extensão e Cultura do Instituto de Aplicação Fernando Rodrigues da Silveira (CAp-UERJ) V. 7 - N. 14 - ABRIL 2018 - ISSN: 2316-9303

DOI: $10.12957 / \mathrm{e}-m o s a i c o s .2018 .33622$

\begin{tabular}{|c|c|c|}
\hline PAN, 2010 & $\begin{array}{l}16 \text { indivíduos com idades entre } \\
6 \text { e } 9 \text { anos, diagnosticados com } \\
\text { autismo de alto funcionamento } \\
\text { e Síndrome de Asperger, } \\
\text { participaram de um programa } \\
\text { de exercícios aquáticos com } \\
\text { duração de } 90 \text { minutos por } \\
\text { sessão, durante o período de } 10 \\
\text { semanas. }\end{array}$ & $\begin{array}{l}\text { Um dos grupos demonstrou } \\
\text { desenvolvimento em habilidades } \\
\text { aquáticas e redução do } \\
\text { comportamento anti- social. }\end{array}$ \\
\hline PAN, 2011 & $\begin{array}{l}15 \text { crianças com idades entre } 7 \\
\text { e } 12 \text { anos com autismo de alto } \\
\text { funcionamento e com Síndrome } \\
\text { de Asperger foram submetidas a } \\
\text { um programa de atividades } \\
\text { aquáticas durante } 14 \text { semanas. }\end{array}$ & $\begin{array}{l}\text { Após a intervenção, todas as } \\
\text { crianças demonstraram } \\
\text { melhorias na força muscular, } \\
\text { resistência, flexibilidade, aptidão } \\
\text { cardiovascular e na execução de } \\
\text { habilidades motoras aquáticas. }\end{array}$ \\
\hline CHELDAVI et al, 2013 & $\begin{array}{l}20 \text { crianças diagnosticadas com } \\
\text { autismo de alto funcionamento } \\
\text { participaram de um programa } \\
\text { de treinamento com exercícios } \\
\text { de equilíbrio } 3 \text { vezes por } \\
\text { semana com duração de } 45 \\
\text { minutos por sessão, totalizando } \\
18 \text { sessões de treinamento. }\end{array}$ & $\begin{array}{l}\text { Após intervenção foram } \\
\text { observadas melhoria no } \\
\text { controle postural dos } \\
\text { participantes. }\end{array}$ \\
\hline $\begin{array}{c}\text { TEIXEIRA- MACHADO, } \\
2015\end{array}$ & $\begin{array}{l}\text { Um jovem de } 15 \text { anos } \\
\text { diagnosticado com TEA, } \\
\text { participou de } 120 \text { sessões de } \\
\text { dançaterapia, com duração de } \\
30 \text { minutos por sessão, } 2 \text { vezes } \\
\text { por semana. }\end{array}$ & $\begin{array}{l}\text { Após a intervenção, o jovem } \\
\text { apresentou melhorias em } \\
\text { aspectos motores, tais como: } \\
\text { como o equilíbrio e a marcha, e } \\
\text { a diminuição dos } \\
\text { comportamentos autísticos. }\end{array}$ \\
\hline
\end{tabular}

Fonte: Elaborado pelo autor

\section{CONTRIBUIÇõES DA ATIVIDADE FÍSICA PARA OS ASPECTOS MOTORES}

Autores como Okuda et al (2010) apontam para a importância da utililização de atividades peceptivo-viso-motoras, sensório motoras, atividades lúdicas, jogos simbólicos, jogos em grupo, atividades sinestésicas, juntamente com estímulos que possam trabalhar a organização espacial e temporal, equilíbrio corporal e coordenação motora fina. Segundo estes autores, estes tipos de atividades podem ser eficazes quando utilizadas no tratamento de crianças com TEA, sobre tudo no que diz respeito ao estímulo de organização e sequenciamento do ato motor, auxiliando assim o aluno a perceber melhor seu próprio corpo para realizar atividades diárias, sociais, escolares e lúdicas.

Anderson-Hanley; Tureck; Schneiderman, (2011) Hilton et al, (2014),Yilmaz et al (2004) já abordam a utilização de exercícios de intensidade vigorosa, exercícios hidroterápicos e a utilização de exergames. Os autores apontam que estes tipos de intervenção vem sendo utilizadas para auxiliar na redução de esteriotipias. 
DOI: $10.12957 /$ e-mosaicos.2018.33622

Outros estudos (FALKENBACH; DIESEL; OLIVEIRA, 2010; MACHADO, 2001; SOUZA; FACHADA, 2012) já apontam para a utilização da terapia psicomotriz, que trata-se da realização de atividades corporais com contato e manipulação de brinquedos, objetos e utensílios do cotidiano, que podem auxiliar no aprimoramento de aspectos motores, indícios de simbolização, comunicabilidade, interação e afetividade.

Também foi possível constatar a presença da utilização de atividades aquáticas (YLMAZ et al, 2004; PAN, 2010; CHICON et al, 2013; HINCKSON et al, 2013). No estudo realizado por

Chicon et al (2013), 15 crianças com idades de 3 anos, sendo 14 crianças com desenvolvimento típico e uma diagnosticada com TEA, participaram de um programa de atividades lúdicas em meio aquático semanalmente com duração de 1 hora por sessão, totalizando 12 sessões.

O programa de atividades foi composto por fundamentos da natação, atividades de adaptação ao meio líquido, atividades de deslocamento, cantigas de roda, exercícios de respiração e flutuação. Como resultados do estudo, foi observado que as atividades lúdicas, realizadas no meio aquático, mostraram-se benéficas para a criança com TEA, principalmente em relação à ampliação de seu repertório motor, a vivência lúdica e também sobre o aspecto do convívio social com seus colegas e professores.

Um dos estudos também demonstrou resultados interessantes com a implementação de um programa de exercícios com o uso de trampolins (LOURENÇO et al., 2016). Participaram deste programa 17 crianças com idades entre 4 e 10 anos, em sessões semanais de treinamento com duração de 45 minutos em cada sessão, durante o período de 20 semanas.

Após a intervenção, pode ser observado que as crianças com TEA obtiveram melhoras na proficiência motora, além de melhorias em outros aspectos importantes, como a coordenação sequencial e simultânea entre os membros inferiores e superiores, melhorias no equilíbrio, na velocidade, na agilidade, na força e na coordenação motora dos membros superiores.

Foi possível também observar intervenções com a utilização de exercícios de equilíbrio (CHELDAVI, 2013) dançaterapia (BOATO, et al, 201 ; MACHADO, 2015), atividades ao ar livre (TODD; REID, 2006) e utilização de atividades de fortalecimento muscular (FRAGALA- PINKHAM et al., 2008). Estas pesquisas demonstraram desenvolvimentos em relação à locomoção (TODD; REID, 2006), à aptidão cardiorrespiratória (FRAGALA- PINKHAM et al., 2008) e melhorias no controle postural (CHEDALVI et al., 2014). 


\section{CONTRIBUIÇõES DA ATIVIDADE FÍSICA SOBRE OS ASPECTOS SócIO-COMUNICATIVOS}

Foi possível identificar que as intervenções promovidas pelos estudos identificados na revisão apresentaram contribuições não somente aos aspectos motores, mas também no estado emocional e comportamental (TOMÉ, 2007) de crianças e jovens com TEA. Estas informações podem ser evidenciadas na metaanálise realizada por Sowa e Meulenbroek (2012), na qual os autores sugerem que as intervenções realizadas com indivíduos com TEA por meio de atividades físicas levaram a uma melhoria de $37 \%$ nas características específicas que autistas possuem, especificamente, melhorias em dificuldades comportamentais e acadêmicas.

Outro dado interessante obtido nesta meta- análise está no fato de as intervenções com programas de exercícios individuais apresentarem resultados mais significativos referentes ao desenvolvimento de aspectos motores e sociais do que as intervenções com atividades coletivas nos indivíduos estudados. No entanto, esta constatação possa advir pelo fato do estudo analisar em seu total 16 produções, demonstrando uma limitação da pesquisa.

O estudo de caso realizado por Falkenbach, Diesel e Oliveira (2010), teve como objetivo observar e analisar questões significativas como a relação da criança com TEA com os professores e colegas; sua iniciativa para brincar; a trajetória de brincadeiras: as situações de jogo e de exercício. Para o objetivo proposto, uma criança diagnosticada com TEA, participou de aulas de psicomotricidade semanais com duração de aproximadamente 60 minutos cada aula por um período aproximado de 4 meses. Como resultados do estudo, pode ser observado que o aluno com TEA demonstrou durante as aulas uma grande afetividade por um dos professores que ministravam as aulas.

Os autores ainda afirmam que em alguns momentos, o aluno com TEA se aproximava de seus colegas demonstrando interação durante algumas atividades com colchões e maior iniciativa para participar de algumas atividades com cordas. Por outro lado, também pode ser observado alguns comportamentos motores repetitivos como pular, correr e rolar, mas também foi constatado a existência de um gosto por atividades de corrida dentro de jogos com fugitivos e de pegadores com os professores.

Bagarollo, Ribeiro e Panhoca (2013), realizaram um estudo de caso com o objetivo de analisar o ato de brincar no desenvolvimento de interações sociais com uma criança de 4 anos diagnosticada com TEA juntamente com outras 3 crianças também diagnosticadas com o mesmo quadro. Estas crianças participaram de sessões terapêuticas semanais com duração de 30 minutos com 0 uso de brinquedos, jogos e atividades lúdicas. Como resultados, foi possível observar que 
DOI: $10.12957 /$ e-mosaicos.2018.33622

em alguns momentos, os indivíduos utilizavam, juntos, o mesmo brinquedo, podendo assim ser possível propor algumas atividades e jogos em grupo.

Pode ser observado também que a criança de 4 anos também demonstrava interesse nos jogos de faz de conta e na simbolização de papéis em determinadas atividades, além de respeitar a sequência de ações e manifestações de conhecimento em relação aos utensílios utilizados para cada ação.

\section{CONCLUSÃo}

Observou-se na literatura uma grande diversidade de estudos que adotaram diferentes tipos de estratégias com a utilização de atividades físicas para a população estudada. Os artigos indicaram a utilização de jogos, atividades de psicomotricidade, práticas esportivas, dinâmicas pedagógicas, atividades aquáticas, gincanas, exercícios de fortalecimento muscular, exercícios de equilíbrio, práticas motoras com trampolins e atividades ao ar livre.

Pode ser observado que prática de atividade física, quando elaborada de forma específica, além de poder auxiliar num desenvolvimento motor mais adequado, proporcionou mais oportunidades de socialização, melhor foco de atenção e melhor performance motora aos indivíduos participantes de cada pesquisa

Diante disso, aconselha- se que mais estudos sejam realizados com o intuito de promover a formulação de programas e itervenções que integrem o exercício físico ao cotidiano de crianças e jovens com autismo.

\section{REFERÊNCIAS}

AMERICAN PSYCHIATRIC ASSOCIATION et al. Diagnostic and statistical manual of mental disorders (DSM-VR). American Psychiatric Pub, 2013.

ANDERSON-HANLEY, Cay; TURECK, Kimberly; SCHNEIDERMAN, Robyn L. Autism and exergaming: effects on repetitive behaviors and cognition. In: Psychology research and behavior management, v. 4, p. 129, 2011.

BAGAROLLO, Maria Fernanda; RIBEIRO, Vanessa Veis; PANHOCA, Ivone. An autistic child's play from the cultural-historical perspective. In: Revista Brasileira de Educação Especial, v. 19, n. 1, p. 107-120, 2013.

BOATO, Elvio Marcos et al. Expressão corporal/dança para autistas-um estudo de caso. In: Pensar a Prática, v. 17, n. 1, 2014.

CHELDAVI, Hakim et al. The effects of balance training intervention on postural control of children with autism spectrum disorder: Role of sensory information. In: Research in Autism Spectrum Disorders, v. 8, n. 1, p. 8-14, 2014. 
DOI: $10.12957 /$ e-mosaicos.2018.33622

CHICON, José Francisco; CARVALHO SILVA DE SÁ, Maria das Graças; SILVA FONTES, Alaynne. Atividades lúdicas no meio aquático: possibilidades para a

inclusão. Movimento, v. 19, n. 2, 2013.

COELHO, M.; SANTO, E. A. Autismo: Perda do Contacto com a Realidade Exterior. 11. 33 f. Monografia (Especialização) - Curso de Formação Continuada, Centro de Formação Contínua de Professores de Ourique, Castro Verde, Aljustrel e Almodôvar, Ouriqe, 2006.

ESPOSITO, Gianluca; PASCA, Sergiu P. Motor abnormalities as a putative endophenotype for Autism Spectrum Disorders. Frontiers in integrative neuroscience, v. 7, 2013.

FALKENBACH, Atos Prinz; DIESEL, Daniela; DE OLIVEIRA, Lidiane Cavalheiro. O jogo da criança autista nas sessões de psicomotricidade relacional. Revista Brasileira de Ciências do Esporte, v. 31, n. 2, 2010.

FONSECA, Vitor da. Da filogênese à ontogên1ese da motricidade. Porto Alegre: Artes, 1988.

FONTES, Ana Catarina Moreira. Desenvolvimento psicomotor em crianças com perturbações do espetro do autismo e desenvolvimento típico: um estudo comparativo. 2013. 81 f. Dissertação (Mestrado) - Curso de Faculdade de Motricidade Humana, Universidade de Lisboa, Lisboa, 2013.

FRAGALA-PINKHAM, Maria A. et al. A fitness program for children with disabilities.In: Physical therapy, v. 85, n. 11, p. 1182-1200, 2005.

FRAGALA-PINKHAM, Maria; HALEY, Stephen M.; O'NEIL, Margaret E. Group aquatic aerobic exercise for children with disabilities. Developmental Medicine \& Child Neurology, v. 50, n. 11, p. 822-827, 2008.

GALLAHUE, D. L.; OZMUN, J. C. Compreendendo o desenvolvimento motor. $3^{a}$ edição. São Paulo. Phorte, 2005.

HILTON, Claudia List et al. Effects of exergaming on executive function and motor skills in children with autism spectrum disorder: a pilot study. In: American Journal of Occupational Therapy, v. 68, n. 1, p. 57-65, 2014.

HINCKSON, Erica A. et al. Physical activity, dietary habits and overall health in overweight and obese children and youth with intellectual disability or autism. In: Research in developmental disabilities, v. 34, n. 4, p. 1170-1178, 2013. 
DOI: $10.12957 /$ e-mosaicos.2018.33622

JASMIN, Emmanuelle et al. Sensori-motor and daily living skills of preschool children with autism spectrum disorders. Journal of autism and developmental disorders, v. 39, n. 2, p. 231-241, 2009.

LARSON, Jennifer $\mathrm{C}$. et al. Acquisition of internal models of motor tasks in children with autism. Brain, v. 131, n. 11, p. 2894-2903, 2008.

LE BOUCH, Jean. O corpo na escola no século XXI: práticas corporais. Phorte, 2008.

LECAVALIER, Luc. Behavioral and emotional problems in young people with pervasive developmental disorders: Relative prevalence, effects of subject characteristics, and empirical classification. Journal of autism and developmental disorders, v. 36, n. 8, p. 1101-1114, 2006.

LÔ, Eliana Noronha; GOERL, Daniela Boccardi. Representação emocional de crianças autistas frente a um programa de intervenção motora aquática. Revista da graduação, v. 3, n. 2, 2010.

LOURENÇO, Carla Cristina Vieira et al. A Eficácia de um Programa de Treino de Trampolins na Proficiência Motora de Crianças com Transtorno do Espectro do Autismo1. Rev. bras. educ. espec, v. 22, n. 1, p. 39-48, 2016.

LOURENÇO, Carla Cristina Vieira et al. Avaliação dos Efeitos de Programas de Intervenção de Atividade Física em Indivíduos com Transtorno do Espectro do Autismo. Rev. bras. educ. espec, v. 21, n. 2, p. 319-328, 2015.

LUCENA, Neide Maria Gomes de et al. Lateralidade manual, ocular e dos membros inferiores e sua relação com déficit de organização espacial em escolares. Estud. psicol.(Campinas), v. 27, n. 1, p. 03-11, 2010.

MACHADO, Maria Lúcia Salazar. Educação e terapia da criança autista: uma abordagem pela via corporal. 2001. 232 f. Dissertação (Mestrado) - Curso de Escola de Educação Física, Programa de Pós-graduação em Ciências do Movimento Humano, Universidade Federal do Rio Grande do Sul, Porto Alegre, 2001.

MATIKO OKUDA, Paola; NUNES MISQUIATTI, Andrea Regina; CAPELLINI, Simone Aparecida. Caracterização do perfil motor de escolares com transtorno autístico. Revista Educação Especial, v. 23, n. 38, 2010.

NETO, Francisco Rosa. Manual de avaliação motora para terceira idade. Artmed Editora, 2009.

ORRÚ, Sílvia Ester. E-Aspectos inerentes ao desenvo/vimento da criança com autismo. Psicopedagogia Online, p. 1-6, 2002. 
DOI: $10.12957 /$ e-mosaicos.2018.33622

PAN, Chien-Yu. Effects of water exercise swimming program on aquatic skills and social behaviors in children with autism spectrum disorders. Autism, v. 14, n. 1, p. 928, 2010.

PAN, Chien-Yu. The efficacy of an aquatic program on physical fitness and aquatic skills in children with and without autism spectrum disorders. Research in Autism Spectrum Disorders, v. 5, n. 1, p. 657-665, 2011.

RICHLER, Jennifer et al. Restricted and repetitive behaviors in young children with autism spectrum disorders. Journal of autism and developmental disorders, v. 37, n. 1 , p. 73-85, 2007.

SANTOS, Isabel Margarida; SOUSA, P. L. Como intervir na perturbação autista. 2005. 47 f. 2005. Tese de Doutorado. Dissertação (Mestrandos em Psicologia Pedagógica)Faculdade de Psicologia e Ciências da Educação da Universidade de Coimbra, Coimbra.

SOUZA,Guilherme Lopes; FACHADA,Rosana. Atividade física para crianças autistas. Reconstruindo a base sócia familiar.EFDeportes.com, Revista Digital. Buenos Aires, Ano 17, № 173, Octubre de 2012.

SOWA, Michelle; MEULENBROEK, Ruud. Effects of physical exercise on autism spectrum disorders: a meta-analysis. Research in Autism Spectrum Disorders, v. 6, n. 1 , p. 46-57, 2012.

TEIXEIRA-MACHADO, Lavinia. Dançaterapia no autismo: um estudo de caso. Fisioterapia e Pesquisa, v. 22, n. 2, p. 205-211, 2015.

TODD, Teri; REID, Greg. Increasing physical activity in individuals with autism. Focus on autism and other developmental disabilities, v. 21, n. 3, p. 167-176, 2006.

TOMÉ, Maycon et al. Educação física como auxiliar no desenvolvimento cognitivo e corporal de autistas. Movimento e Percepção, v. 8, n. 11, 2007.

TREVARTHEN, Colwyn; DANIEL, Stuart. Disorganized rhythm and synchrony: Early signs of autism and Rett syndrome. Brain and Development, v. 27, p. S25-S34, 2005.

WROTNIAK, Brian $\mathrm{H}$. et al. The relationship between motor proficiency and physical activity in children. Pediatrics, v. 118, n. 6, p. e1758-e1765, 2006.

YILMAZ, Ilker et al. Effects of swimming training on physical fitness and water orientation in autism. Pediatrics International, v. 46, n. 5, p. 624-626, 2004.

Recebido em 14 de agosto de 2017. Aceito em 05 de outubro de 2017. 